\title{
SISTEMA DE DIREÇÃO ACIONADO ELETRICAMENTE PARA PLATAFORMA AGRícolA
} MULTIFUNCIONAL

\author{
Júlia de M. Brittes*, Angel Pontin Garcia.
}

\begin{abstract}
Resumo
In this project it was implemented, through simulation, a direction system Steer-by-Wire eletrically powered for a multifunctional agricultural plataform, with levels of freedom equal to the number of wheels, when calculated the platform engine torque and considering their typical draft resistance (rolling, bulldozing, soil compactation) and its steepness, it is possible to correct efficiently the Ackermann error in a system driven by an eletric engine, through which is allowed to reach an appropriate angular correction of the positions defined by the operator.
\end{abstract}

\section{Palavras-chave:}

Agricultura de Precisão, Máquinas Agrícolas, Veículo Não Tripulado

\section{Introdução}

O uso da energia elétrica para acionamento de componentes auxiliares de máquinas agrícolas reduz significativamente seu consumo de combustível e permite aplicar sistemas de maior eficiência e flexibilidade de operação, com controle funcional mais rápido, exato e preciso.

Neste trabalho, com o objetivo de se desenvolver e testar um sistema de direção acionado eletricamente para uma plataforma agrícola multifuncional de $1 \mathrm{~m}^{2}$ para transporte máximo de 1 tonelada, implementou-se, por simulação, um sistema elétrico de direção Steer-by-Wire (SBW), cujo grau de liberdade é seu número de rodas, podendo-se corrigir, assim, com mais eficiência, o Erro de Ackerman (Siegwart et al (2004)). Foram estudados o Cálculo de Ackermann e sua aplicação através de um motor elétrico de corrente contínua (MECC). Através do cálculo do torque-motor da plataforma, calculado de forma a se considerarem a resistência típicas de projeto (rolamento, de cava, compactação do solo) de diversos tipos de solo e sua declividade (Apostolopoulos et al. (2001) e Barger, E. L (1963)), a simulação demonstrou que o uso do modelo de Ackermann apresenta uma correção angular adequada às posições definidas pelo operador.

\section{Resultados e Discussão}

O motor DC a ser usado para cada roda foi definido pela demanda de torque necessário ao avanço da plataforma numa dada velocidade, definida nessa simulação como $1 \mathrm{~m} \mathrm{~s}^{-1}$. Esse torque foi calculado a partir das resistências que um solo agrícola impõe às rodas, baseado em Apostolopoulos e Barger, para os solos agrícolas argilosos médio, e uma roda de diâmetro 17 " e largura 8".

Para as simulações, a partir do cálculo de Ackermann, utilizou-se um controlador PID em conjunto com um motor DC, chegou-se ao diagrama montado em Matlab/SIMULINK da Figura 1.
Os parâmetros utilizados nas simulações foram os do motor elétrico da marca Motron, modelo MR210. O sistema foi acionado por meio de uma curva senoidal, o ângulo de esterçamento obtido foi calculado a partir do erro de Ackermann, apresentado no Gráfico 1. Neste gráfico pode-se observar que há adequação da posição de saída a partir de uma posição de entrada.

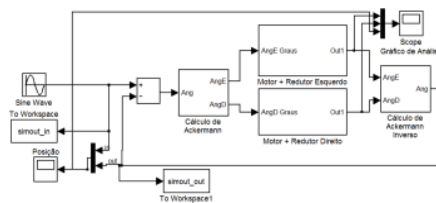

Figura 1 - Modelo principal implementado no Simulink

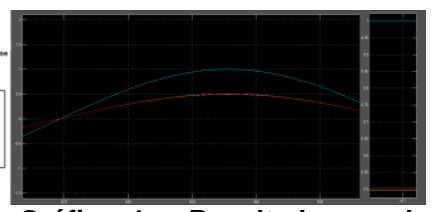

Gráfico 1 - Resultado gerado na simulação

\section{Conclusões}

A partir do cálculo das resistências típicas $(F)$ o torque para cada roda deverá ser maior que $284 \mathrm{~N} \mathrm{~m}$ para haver movimento e, para o caso de três das rodas derraparem, o torque a ser empregado na roda que não derrapa deverá ser maior que $1972 \mathrm{~N} \mathrm{~m}$.

As senóides geradas no gráfico 1 demonstram que, quanto maior o esterçamento da direção, maior será o erro a ser corrigido para o esterçamento de cada roda e da mesma forma, quanto menor o esterçamento da roda menor será o erro que o cálculo de Ackermann terá de corrigir.

\section{Agradecimentos}

Agradecimentos aos membros do LIC, ao meu orientador Angel P. G., ao colega João Marcos Q. e à minha família.

\footnotetext{
${ }^{1}$ Siegwart, R.; Nourbakhsh, I. R. Introduction to Autonomous Mobile Robots Primeira Edição. Editora MIT (Massachusetts Institute of Technology), 33-74 e 260-278, 2004

2 Apostolopoulos, D. D. Analytical Configuration of Wheeled Robotic Locomotion. Tese (Doutorado) - Robotics Institute, Carnegie Mellon University, Pittsburgh, PA, 2001.

3 Barger, E. L (Coaut. de). Tratores e seus Motores. São Paulo, SP: Edgard Blucher. 207-231, 1963
} 